\title{
Influência do histórico de letramento dos candidatos na mobilização de práticas letradas na redação de vestibular
}

Influence of the candidates' literacy history in the mobilization of literacy practices in the composition test of the university entrance examination

Elizabeth Maria da Silva*

Universidade Federal de Campina Grande

Campina Grande - Paraíba / Brasil

Denise Lino de Araújo**

Universidade Federal de Campina Grande

Campina Grande - Paraíba / Brasil

\begin{abstract}
RESUMO: este artigo tem dois objetivos: (1) descrever o histórico de letramento dos candidatos (HL) ao vestibular da Universidade Federal de Campina Grande (UFCG) e (2) analisar as associaçōes entre a mobilização de práticas letradas nas redaçōes de vestibular e o HL dos candidatos. Os dados indicam que o histórico de letramento constituído por práticas do letramento escolar não se mostrou suficiente para que os candidatos atendessem às práticas letradas requeridas pelo exame. No entanto, aqueles que demonstraram um HL pontuado por experiências de escrita adquiridas fora da escola atenderam de modo mais adequado ao que fora solicitado na produção textual. PALAVRAS-CHAVE: prova de redação, práticas letradas, histórico de letramento.

ABSTRACT: this article has two objectives: (1) to describe the Literacy History (LH) of those candidates to entrance exam of the Federal University of Campina Grande (UFCG) and (2) to analyze the relationship between the mobilization of literacy practices both in the compositions and in the candidates' LH. The data indicate that the Literacy History composed of school literacy practices was not enough for candidates to attend the literacy practices required by the exam. However, those who demonstrated an LH punctuated by writing experiences acquired outside the school attended more adequately to what was requested in textual production. KEYSWORDS: composition test, literacy practices, literacy history.
\end{abstract}

* professoraelizabethsilva@gmail.com

**linodenise@yahoo.com.br 


\section{Introdução}

$\mathrm{Na}$ literatura sobre escrita, há vários estudos relativos à redação de vestibular. Temos, por exemplo, pesquisas referentes à textualidade das redaçōes (cf. LEMOS, 1977; PÉCORA, 1986; ROCCO, 1981; COSTA VAL, 1999; LIMBERT, 2006), bem como estudos voltados para a caracterização da redação de vestibular como um gênero textual (cf. PILAR, 2001; PAVANI; KÖCHE, 2006; ZANUTTO; OLIVEIRA, 2004; HILA, 2007). Todas essas pesquisas têm dois pontos em comum: nas provas de redação analisadas é exigida a produção de dissertações escolares e a análise feita pelos pesquisadores limita-se aos exemplares das redações.

Diante desse quadro, nos últimos anos, vimos desenvolvendo pesquisas sobre as provas de redação aplicadas pela Universidade Federal de Campina Grande, cujos resultados têm evidenciado o efeito retroativo ${ }^{1}$ da teoria de gêneros textuais na elaboração dessas provas (SILVA; LINO DE ARAÚJO, 2005; 2006a; 2006b; 2006c; 2006d). Desde o vestibular aplicado em 2005, ${ }^{2}$ são propostas duas situaçóes de escrita que materializam dois gêneros textuais - artigo de opinião ou relato de experiência (UFCG 2005); depoimento ou carta denúncia (UFCG 2006); carta protesto ou memória, (UFCG 2007); reportagem ou análise comparativa de poemas (UFCG 2008); abaixo-assinado ou artigo jornalístico (UFCG 2009) e diálogo ou anúncio publicitário (UFCG 2010).

Esse redirecionamento na prova de redação motivou-nos a analisar que correlação poderia ser estabelecida entre as práticas letradas mobilizadas nas redaçôes e o histórico de letramento dos candidatos (SILVA, 2009). Estamos entendendo o HL como as experiências que os sujeitos dizem ter em relação às práticas de leitura e de escrita com as quais têm familiaridade ou conhecimento.

Nesse contexto, dois são os objetivos do presente artigo: (1) descrever o histórico de letramento dos candidatos e (2) analisar as associações entre a mobilização de práticas letradas nas redações de vestibular e HL dos candidatos.

\footnotetext{
${ }^{1} \mathrm{O}$ efeito retroativo é o impacto ou a influência que mecanismos de avaliação podem exercer no processo de ensino/aprendizagem, bem como nos seus participantes e no produto desse processo (cf. SCARAMUCCI, 2001).

${ }^{2} \mathrm{O}$ vestibular aplicado por essa instituição é relativamente recente, já que a UFCG se desmembrou da Universidade Federal da Paraíba em 2002. Desde o primeiro ano da realização do seu processo seletivo, a prova de redação é pautada na solicitação da escrita de gêneros textuais.
} 
Quanto à organização, este artigo está dividido em três partes. $\mathrm{Na}$ primeira, explicitamos os princípios teóricos adotados; na segunda, descrevemos os aspectos metodológicos da pesquisa, e, na terceira parte, fizemos a análise do histórico de letramento dos candidatos.

\section{A constituição do histórico de letramento}

Dentre as abordagens de letramento - Autônoma e Ideológica (STREET, 1984), Crítica (BARTON; HAMILTON, 2000; GEE, 2000), Pragmática (MEY, 2001) e Retórica (BAZERMAN, 2007), optamos pela Crítica. Nessa abordagem, as práticas de leitura e de escrita são entendidas a partir da correlação entre o contexto sócio-histórico e ideológico, no qual são utilizadas e a história de vida do sujeito. No universo dessa história de vida, destacamos o histórico de letramento.

Pesquisadores têm revelado que a história de vida de professores e de alunos de graduação é um dos elementos que interferem na sua atuação profissional dos mesmos, na sua prática em sala de aula.

Guedes-Pinto (2001), Guedes-Pinto et al. (2005) e Signorini (2005) analisaram relatos sobre a história de leitura de professores, observando que instâncias (escolar, religiosa, familiar, etc.) e / ou pessoas (pais, vizinhos, professores, etc.) contribuíram com o desenvolvimento da prática de leitura desses docentes. Semelhante trabalho foi realizado por Almeida (2001), que analisou a correlação entre as práticas de leitura do professor, a constituição de uma identidade profissional e a atuação pedagógica.

As pesquisas referidas acima evidenciam a influência da história de leitura dos professores na sua atuação em sala de aula. Dependendo do contato que estabeleciam com as diferentes agências letradas, tendiam a incorporar suas práticas de modo que as transferiam, muitas vezes, para outros eventos. Práticas religiosas, familiares, acadêmicas transpareciam, em geral, na práxis docente. Isso demonstra que a escola está dividindo com outras agências seu papel de promotora da inserção na cultura letrada.

Os estudos supracitados são produtivos, haja vista que nos levam a pensar a respeito da influência que o HL dos sujeitos pode exercer nas suas atitudes, de maneira que estes podem realizar um processo de transposição de práticas letradas de um evento de letramento para outro.

Como estamos imersos em uma sociedade cada vez mais dinâmica e complexa e, em consequência disso, temos a possibilidade de ter acesso a diferentes tipos de letramento, há sujeitos multiletrados. Em função de 
estarem, muitas vezes, em contato com diferentes tipos de letramento familiar, religioso, midiático, digital, escolar, entre outros -, esses sujeitos demonstram práticas de escrita diferenciadas oriundas desses letramentos.

Nesse sentido, entendemos que a escola parece não ser mais a principal agência de letramento como defende Kleiman (1995), mas outras agências, como a familiar, a religiosa, a midiática (cf. LINO DE ARAÚJO, 2004), influenciam significativamente os sujeitos. Silva (2009) percebeu que o atendimento às práticas requeridas pela prova de redação deu-se mais pelo contato que alguns candidatos tinham com o letramento literário, familiar, religioso e midiático do que com o escolar.

Dessa forma, começa-se a reconhecer eventos e práticas de letramento em variadas agências, tais como a igreja, a escola, os sindicatos, como bem destacam Barton e Hamilton (2000, p.11) "há diferentes letramentos associados a diferentes domínios de vida, como a família, o trabalho e a escola”.

Diferentemente da alfabetização, que é temporária e termina assim que o sujeito conclui seus primeiros anos de escolarização, o letramento é um processo constante e infinito, visto que, a cada dia, novas agências, novas situações sociocomunicativas surgem e, consequentemente, novos tipos de letramento, novos eventos, exigindo determinadas práticas letradas, às vezes peculiares, às vezes já conhecidas, apenas atualizadas. O contato com tais práticas contribui para a constituição do histórico de letramento dos sujeitos. Por isso, a importância de se conhecer esse HL antes de analisar determinadas práticas por si mesmas, descontextualizadamente. O sujeito que escreve tem uma história da qual não se desprende no momento de escrever seu texto, pelo contrário, recorre, em geral, a ela para atender às exigências de determinados eventos de letramento.

É importante destacar que somos cientes de que o HL não é elemento determinante das atitudes e comportamentos dos sujeitos, é, então, um dos elementos que podem interferir nas práticas por eles demonstradas em eventos de letramento.

\section{Aspectos metodológicos}

Neste item são apresentados os aspectos metodológicos da pesquisa, organizados da seguinte maneira: primeiro, são definidos o tipo e a natureza da pesquisa; logo em seguida, é apresentado o corpus analisado e, por fim, são descritos os instrumentos e procedimentos da coleta de dados. 


\section{Tipo de pesquisa}

Trata-se de uma pesquisa descritivo-interpretativista (cf. MOREIRA; CALEFFE, 2006; ANDRÉ, 1995; MOITA LOPES, 1994), cujo corpus foi constituído de quatro conjuntos de dados. Desses quatro, três são de natureza documental e dizem respeito (1) às provas de redação aplicadas pela Comissão de Processos Vestibulares, nos vestibulares regular e especial ${ }^{3}$ da UFCG 2007, (2) a uma amostragem de redações produzidas nesses vestibulares e (3) ao questionário socioeconômico e cultural respondido pelos vestibulandos cujas redações foram objetos de estudo deste trabalho. O quarto conjunto de dados é de natureza opinativa e diz respeito às entrevistas semiestruturadas que foram realizadas com os candidatos selecionados. Para melhor compreensão da análise, descreveremos, a seguir, os dados mencionados no primeiro e segundo conjuntos.

\section{Descrição do corpus}

\section{Práticas letradas requeridas nas provas de redação da UFCG 2007}

Nas provas de redação aplicadas nos vestibulares regular e especial da UFCG em 2007, há uma relação intragênero, já que no interior do gênero prova de redação é solicitada a produção de outros gêneros textuais, carta protesto e memória (vestibular regular 2007); palestra e resenha (vestibular especial 2007), para os quais são apresentadas condiçóes de produção a exemplo de objetivo, público-alvo, ambiente de circulação.

Nessa relação intragênero, os candidatos deparam-se com dois jogos enunciativos: o proposto pela prova (doravante JEP), que se deu ao assumirem o papel social indicado nas instruções referentes ao gênero escolhido e escreverem para o locutor sinalizado -, e outro escolar (doravante JEE), que se deu ao produzirem um dos gêneros texuais indicados com o objetivo de serem avaliados pela banca corretora do vestibular, desconsiderando, assim, o destinatário apresentado na situação comunicativa proposta. A participação no jogo enunciativo da prova é uma das práticas letradas requeridas pelo exame, assim como a adequação do texto ao tema proposto e uso do registro escrito formal da língua portuguesa.

\footnotetext{
${ }^{3} \mathrm{O}$ vestibular especial é realizado no meio do ano. Nesse vestibular, são abertas inscriçôes para um número menor de cursos, os quais são oferecidos nos campi da UFCG localizados em cidades circunvizinhas a Campina Grande.
} 
O JEP é sinalizado nas instruções dadas para a produção de cada gênero, em um item denominado SITUAÇÃO, no qual o enunciado inicia-se pelo verbo "imagine", ou seja, a instrução orienta para uma escrita fundamentada numa criação, numa ordem para o candidato "esquecer" a sua posição enunciativa de vestibulando, e assumir outra: cidadão atuante em prol das melhorias da condição do homem do campo, descendente de um homem do campo, ou resenhista de veiculos de comunicação escrita e profissional que teve dificuldade de escolher sua profissão.

Tendo assumido uma das posições enunciativas indicadas, o candidato deverá produzir o texto, inspirado em um dos gêneros, que será supostamente publicado em meios de comunicação. A memória e a carta protesto seriam teoricamente publicadas na Revista Nordeste e a resenha, na Revista Época. Já a palestra deveria ser escrita com o objetivo de ser proferida para um público formado por jovens e seus pais. A referência a essas revistas, bem como a indicação do público-alvo da palestra contribuem para a simulação do contexto comunicativo dos gêneros textuais apresentados.

As situaçóes comunicativas propostas nas provas, assim como acontece normalmente na escola, não se concretizam efetivamente, mas servem para orientar a escrita dos candidatos, de modo que não pensem que a escrita é um dom (cf. SERCUNDES, 1998) e, portanto, que não é necessário conhecer o objetivo do texto nem o interlocutor alvo antes de escrever. É característico dessa situação de escrita não circular publicamente, a menos que a instituição elaboradora do concurso decida publicar, em sites ou em livros, as melhores redações produzidas no vestibular, como acontece, por exemplo, com os textos escritos nos vestibulares da UNICAMP (2003).

A inserção no jogo enunciativo proposto na prova implica, além de adequar o texto às condições de produção, respeitar as estruturas composicionais dos gêneros, as quais foram, brevemente, descritas nas provas no item denominado $A T E N C ̧ \tilde{A} O$ !!! Essa descrição aponta para uma relação entre o ingresso nesse jogo e o acionamento de práticas letradas diversas, pois, para assumir uma das posiçôes enunciativas indicadas, os candidatos devem recorrer a práticas diversas, não apenas as escolares.

Sendo assim, as provas de redação elaboradas e aplicadas pela UFCG configuram-se como eventos de letramento complexos, uma vez que requerem práticas letradas oriundas de diferentes agências, e não apenas da escolar, como tradicionalmente acontece nesse tipo de prova.

Portanto, o multiletramento está subjacente a essa prova de redação, já que os candidatos multiletrados, aqueles que têm familiaridade com diferentes 
práticas, demonstraram desempenho satisfatório na redação desse vestibular, conforme mostramos mais adiante.

\section{Redações produzidas pelos candidatos}

Em um universo de 5.850 redações produzidas nos vestibulares aplicados pela UFCG em 2007 (4.300 no regular e 1.550 no especial), coletamos uma amostragem de $5 \%$ do total de redaçóes produzidas em cada vestibular (200 no regular e 100 no especial). Organizamos tais redações em três categorias: (1) candidatos que participam do jogo enunciativo da prova; (2) candidatos que participam parcialmente do jogo enunciativo da prova; e (3) candidatos que participam do jogo enunciativo escolar. Vejamos a TAB.1:

\section{TABELA 1}

Participação no jogo enunciativo - Legenda JEP Jogo Enunciativo da Prova; JEE - Jogo Enunciativo Escolar

\begin{tabular}{c|c|c|c|c}
\hline & JEP & Parcialmente JEP & JEE & Total \\
\hline Vestibular regular & 9 & 71 & 120 & 200 \\
Vestibular especial & 10 & 22 & 68 & 100 \\
\hline
\end{tabular}

Considerando os números evidenciados na TAB. 1 - pouca recorrência de candidatos que participaram do JEP e grande recorrência de candidatos que participaram do JEE -, optamos por analisar esses dados que evidenciam o desempenho extremo no processo de produção textual no vestibular.

Conforme mostramos no item anterior, nas provas de redação aqui focalizadas, foram propostos os seguintes gêneros textuais: memória e carta protesto (vestibular regular), palestra e resenha (vestibular especial). Em relação às redaçóes cujos candidatos participaram do jogo enunciativo da prova, foram analisadas memórias, palestras e resenhas, pois não encontramos, na amostragem coletada, exemplos prototípicos de cartas protesto. Quanto às redações cujos candidatos participaram do jogo enunciativo escolar, apenas as resenhas não foram analisadas, já que, nos dados coletados, não identificamos exemplares em que os vestibulandos desrespeitassem totalmente as práticas exigidas no gênero resenha.

\section{Instrumentos e procedimentos da coleta de dados}

$\mathrm{Na}$ tentativa de conhecermos um pouco mais sobre os candidatos, suas experiências com a leitura e com a escrita, realizamos uma entrevista 
semiestruturada. Esse é um dos instrumentos de coleta de dados mais utilizados em pesquisas, sobretudo naquelas em que se busca averiguar o nível de letramento dos sujeitos (VÓVIO; SOUZA, 2005). Muitos pesquisadores preferem fazê-la face a face com os informantes. Nós também já recorremos, em pesquisas anteriores, a essa modalidade, mas obtivemos, em geral, pouco êxito - os informantes não compareciam ao local determinado, ligavam remarcando, desistiam e, quando iam, ficavam, muitas vezes, tímidos e inibidos.

Diante dessas nossas experiências que, certamente, é a de muitos pesquisadores, optamos por realizar a entrevista por telefone. Imaginamos que os entrevistados sentir-se-iam mais à vontade para responder às questôes, já que não estaríamos frente a frente, além de que não precisaríamos nos deslocar para nenhum lugar, nem eles tampouco. A maioria desses candidatos não morava em Campina Grande, e sim em outras cidades como em João Pessoa e Cajazeiras, e mesmo em outros estados, como Pernambuco e Rio Grande do Norte, fator que poderia atrasar a coleta dos dados.

O fato de termos feito a entrevista por telefone não implicou a perda de sua função social, haja vista que tivemos as mesmas preocupações que teríamos se fôssemos realizá-la presencialmente:

criar um clima propício à "abertura da alma" do entrevistado, para que pudéssemos obter dados relevantes, confiáveis e ricos para a pesquisa; não sugerir respostas; respeitar o/a entrevistado/a; não o interromper; não o intimidar; estabelecer um clima de confiança; utilizar uma linguagem próxima à dele/dela; procurar falar menos do que ele/ela, mas insistir no que quer (SILVEIRA, 2002, p.122-123).

Além disso, é bastante comum os jovens se comunicarem entre si e com pessoas de outras faixas etárias por telefone, sobretudo após a popularidade dos celulares, acompanhada de várias promoções apresentadas pelas operadoras de telefonia. E ainda, na esfera jornalística, são feitas, com frequência, entrevistas por telefone. É inegável, portanto, que o telefone é uma das tecnologias mais utilizadas no nosso dia a dia.

$\mathrm{Na}$ TAB. 2, explicitamos a quantidade de candidatos com os quais conseguimos estabelecer contato, distribuída a partir do atendimento às práticas letradas exigidas na redação e da forma pela qual foi realizada a entrevista com eles. 
TABELA 2

Participantes da pesquisa distribuídos conforme jogo enunciativo e tipo de entrevista

\begin{tabular}{c|c|c|c|c|c}
\hline $\begin{array}{c}\text { Jogos } \\
\text { enunciativos }\end{array}$ & $\begin{array}{c}\text { Candidatos } \\
\text { selecionados }\end{array}$ & $\begin{array}{c}\text { Entrevistados } \\
\text { por telefone }\end{array}$ & $\begin{array}{c}\text { Entrevistados } \\
\text { por e-mail } \\
\text { a entrevista }\end{array}$ & $\begin{array}{c}\text { Candidatos que } \\
\text { não concederam }\end{array}$ & $\begin{array}{c}\text { Candidatos } \\
\text { incomunicáveis }\end{array}$ \\
\hline JEP & $19^{4}$ & 6 & 7 & 0 & 6 \\
JEE & $50^{5}$ & 0 & 4 & 34 & 12 \\
\hline Total & 69 & 6 & 11 & 34 & 18 \\
\hline
\end{tabular}

Conforme a TAB. 2, dos sessenta e nove candidatos selecionados para a entrevista, só conseguimos entrar em contato com dezessete; trinta e quatro recusaram-se a participar da pesquisa e dezoito não tinham mais o mesmo número de telefone indicado na ficha de inscrição do vestibular.

Dos dezessete candidatos com os quais conseguimos estabelecer contato, seis aceitaram realizar a entrevista por telefone e autorizaram a gravação e onze nos pediram que enviássemos as questōes por e-mail, porque teriam mais tempo para ler e responder às perguntas, já que, segundo eles, estavam muito atarefados.

Portanto, uma parte das entrevistas foi realizada por telefone e a outra por e-mail. Sabemos que a utilização desses instrumentos implicou a não visualização das reações dos candidatos, seus gestos e movimentos faciais, mas, não era, de fato, o nosso objetivo observar esses elementos.

\section{Histórico de letramento dos candidatos ao vestibular UFCG 2007 \\ Discurso dos candidatos sobre a prova de redação}

Apresentamos neste item, com base na entrevista realizada com os candidatos, a experiência que eles disseram ter com práticas letradas. As falas desses sujeitos permitiram-nos observar alguns pontos que podem demarcar as fronteiras do histórico de letramento dos que participaram do jogo enunciativo proposto na prova e dos que participaram do jogo enunciativo

\footnotetext{
${ }^{4}$ Essas 19 redações são as únicas, na amostragem, em que os candidatos participaram do JEP.

${ }^{5}$ Essas 50 redações foram selecionadas do universo de 188 redaçôes cujos candidatos participaram do JEE (vide TAB. 1).
} 
escolar. Vejamos a TAB. 3, na qual distribuímos os candidatos de acordo com a participação nesses jogos enunciativos:

TABELA 3

Candidatos que participaram do JEP e os que participaram do JEE 6

e os gêneros textuais escolhidos

\begin{tabular}{l|c|c}
\hline \multicolumn{3}{c}{ PROVAS DE REDAÇÃO UFCG EM 2007} \\
\hline & JEP & JEE \\
\hline MEMÓRIA & C3 e C4 & C14 e C15 \\
PALESTRA & C8 e C9 & C16 e C17 \\
RESENHA & C11 e C13 & -7 \\
CARTA PROTESTO & -8 & $\mathrm{C} 1$ e C2 \\
\hline
\end{tabular}

Os vestibulandos, independentemente do jogo enunciativo no qual ingressaram, disseram ter estudado gêneros textuais na escola e preferir a produção desses à escrita de dissertações escolares. Isso nos leva a pensar que eles já tinham uma experiência prévia com o modelo de redação solicitado no vestibular da UFCG e também que preferiam esse modelo ao modelo de dissertação. Vejamos a opinião de alguns candidatos quanto à solicitação de gêneros textuais no vestibular da UFCG.

Registro $1^{9}$

C1. Acredito que esta variedade textual é muito importante para o pleno desenvolvimento e capacitação do aluno, procurando deixá-lo mais completo e apto para qualquer situação. Prefiro gêneros, pois é relativamente mais informal, permitindo a expressão da idéia como se tem de fato, sem ter preocupaçóes maiores com a generalidade de determinado assunto, considero, de certa forma, mais subjetivo [Grifos nossos].

\footnotetext{
${ }^{6} \mathrm{C}$, nesta tabela, significa Candidato.

${ }^{7}$ Nos dados coletados, não encontramos resenhas cujo candidato não tenha atendido às práticas requeridas na produção de tal gênero.

${ }^{8}$ Nos dados coletados, não encontramos cartas protesto cujo candidato tenha atendido às práticas requeridas na produção de tal gênero.

${ }^{9}$ Denominamos de registros as respostas dadas pelos candidatos às perguntas feitas na entrevista.
} 
Registro 2

C2. Eu... acho bacana eh... esses gêneros que diferenciam um pouco e assim... abrem..... eh abrem um pouco a cabeça do aluno para... para ele pensar em outras coisas assim e para que ele é... eh.. para que ele consiga relacionar mais o que ele tá escrevendo com o cotidiano dele, que muitas vezes isso não acontece com os temas de dissertação. [Grifos nossos].

Registro 3

C16. É sempre bom inovar. A tradicional dissertação limitava o estudante a estudar apenas um gênero de redação entre tantos outros que existem. [Grifos nossos].

Registro 4

C17. Interessante. Porque força o vestibulando a se aprofundar em outros tipos de texto além da dissertação. [Grifos nossos].

Registro 5

C13. Essa forma de cobrança é positiva por forçar o estudante a conhecer os diferentes gêneros textuais. [Grifos nossos].

Podemos observar nos exemplos acima que tanto os candidatos que participaram do JEE $(\mathrm{C} 16, \mathrm{C} 17)$ quanto os que participaram do JEP $(\mathrm{C} 1, \mathrm{C} 2$ e C13) criticaram, (in)diretamente, a dissertação escolar ao mesmo tempo que defenderam a produção de gêneros textuais pelo fato de que esses forçam o vestibulando a se aprofundar em outros tipos de texto além da dissertação, permitindo pensar em outras coisas, de modo que não fiquem limitados a estudar apenas um gênero de redação entre tantos outros que existem.

Com isso, sugerem que a produção dos gêneros textuais favorece uma maior autonomia para escrever, de modo que não precisarão ficar presos a uma estrutura fixa, como acontece na escrita de uma dissertação. Além disso, parecem entender que a produção de gêneros amplia os horizontes dos alunos que terão a oportunidade de escrever textos que lhe são mais próximos, relacionando o que ele tá escrevendo com o seu cotidiano. Tal prática, salienta o candidato 2, contribui para que os alunos sejam mais reflexivos e conheçam outros gêneros, e não somente a dissertação, cujos temas, muitas vezes, não se referem ao dia a dia dos escritores.

Tendo constatado que os candidatos preferiam a produção de gêneros textuais, indagamos se seus professores trabalhavam esse modelo de texto em sala de aula. A resposta foi quase unânime - sim -, somente dois candidatos disseram ter estudado dissertação, outro disse que não produziu redações 
quando cursou a terceira série do ensino médio e outro disse que não se recordava de tê-los estudado. Os que afirmaram ter estudado gêneros citaram alguns exemplos como artigo de opinião, depoimento, cartas, resenha, sugerindo-nos que seus professores aderiram à concepção de escrita subjacente aos Parâmetros Curriculares Nacionais (2006), pautada na concepção de gêneros discursivos / textuais.

Uma vez indicada nesses documentos, tal concepção norteia o conteúdo de língua portuguesa apresentado nos livros didáticos, que são o principal instrumento didático ao qual o professor recorre para ministrar suas aulas. Considerando que nos vestibulares realizados pelas instituições públicas sediadas na cidade de Campina Grande vem sendo exigida a produção de gêneros textuais, os professores talvez tenham sentido a necessidade de se adequar a tal realidade: como foi um terceiro ano voltado pro vestibular, a professora... ela trabalhava... ela trabalhou gêneros diferentes, já pensando nessa... eh nesse... costume que a UFCG tava desenvolveno de trabalhar com gêneros diferentes, salienta o candidato 3 .

Embora a preferência pela produção de gêneros textuais não tenha se mostrado um elemento diferenciador entre os candidatos que participaram do jogo enunciativo proposto e os que participaram do jogo enunciativo escolar, não desconsideramos que o contato com gêneros na agência escolar pôde têlos influenciados na escrita da redação. As práticas letradas com as quais os candidatos tiveram contato na agência escolar poderiam ter sido acionadas na agência acadêmica, que, dentre outras práticas, também exige algumas práticas escolares. Logo, a experiência, o contato com gêneros em sala de aula, pode ter favorecido certa familiaridade com o tipo de prova aplicado pela UFCG.

No caso dos candidatos que participaram do JEE, outros fatores devem ter interferido, de forma mais intensa, na produção textual, conforme os próprios vestibulandos afirmaram quando indagados se já haviam escrito antes o gênero por eles escolhido no vestibular: Eu sempre estudei, li e escrevi esse gênero na escola. Não senti muita dificuldade de escrevê-lo não. O que contou foi o nervosismo (C14), já havia lido e estudado um pouco sobre ele tanto na escola como no cursinho. Mas não pratiquei o suficiente e na redação do vestibular não me lembrava ao certo da sua estrutura e, pelo menos é o que penso, acho que isso me prejudicou (C15) [grifos nossos]. Em suas afirmativas, os candidatos $14 \mathrm{e}$ 15 tentam preservar a imagem da escola onde estudaram, dizendo que haviam estudado o gênero produzido no vestibular, ao mesmo tempo, se culpam pelo desempenho insatisfatório na escrita da redação. De acordo com as respostas, 
o responsável por tal desempenho não foi a escola, esta os preparou, cumpriu seu papel, mas os próprios candidatos que, por nervosismo ou por não exercitarem o ato de escrever, prejudicaram-se na prova de redação. Em outros termos, sofreram o efeito retroativo negativo do vestibular.

A formulação do conceito de efeito retroativo (backwash ou washback) decorre da constatação de que a avaliação, sobretudo externa e seletiva, exerce influência sobre a perspectiva teórico-metodológico do ensino, bem como sobre o comportamento e as atitudes dos participantes, antes, durante e depois do exame (cf. SCARAMUCCI,1999, 2001, 2002; AVELAR, 2001; CORREIA; 2003; LANZONI, 2004). O abalo no componente psicológico - nervosismo, ansiedade, desconcentração no momento da realização da prova - é um efeito retroativo negativo que pode ocorrer no vestibular, tendo em vista seu caráter seletivo e classificatório.

Nesse sentido, entendemos que os comentários dos candidatos supracitados são pertinentes, pois vêm confirmar que, na análise de um texto, não apenas os aspectos linguísticos devem ser considerados mas também outros fatores como a experiência com leitura e escrita por parte dos candidatos e por parte dos pais, além da experiência dos vestibulandos com o gênero produzido na prova de redação do vestibular. Comentaremos sobre esses fatores nos subitens seguintes.

\section{Experiência dos candidatos com a leitura e escrita}

Em relação à experiência dos candidatos com a leitura, verificamos que tanto os que participaram do jogo enunciativo escolar quanto os que participaram do jogo enunciativo da prova afirmaram que gostavam de ler. Porém, os dados demonstram que as práticas de leitura de um e outro grupo são diferentes entre si. Os primeiros declararam que a leitura realizada vinculava-se, quase sempre, a apenas um domínio, a exemplo de leitura da Bíblia, de livros técnicos, literatura, ou de textos escolares. Ao destacarem as preferências pela leitura, esses candidatos o fizeram de forma bastante objetiva e direta, sem explicitar se eram acostumados a ler e se liam por prazer. São exemplo de suas declarações: [leio] assuntos relacionados à religião e livros técnicos (C17); Não gosto muito de ler, mas, quando leio me envolvo com a leitura e esta se torna prazerosa. Artigos, dissertaçóes (C15). Dentre os candidatos que integram esse grupo, a exceção é o 16, que declarou ler textos de diferentes domínios, incluindo literatura, textos informativos e opinativos. 
Com relação à escrita, percebemos algo semelhante nos candidatos que participaram do jogo enunciativo escolar: dos quatro que foram entrevistados, dois disseram escrever apenas textos escolares, sobretudo dissertação; o terceiro afirmou que escrevia somente textos relacionados ao trabalho e o quarto disse que gostava de escrever crônicas por prazer. Malgrado esses candidatos tivessem contato com a leitura e com a escrita, este não era um contato heterogêneo, com práticas plurais nem ecléticas, e, sim, com práticas realizadas segundo a necessidade escolar ou profissional.

Já os candidatos que participaram do jogo enunciativo da prova afirmaram ler de forma mais diversificada, sendo bastante recorrente, na entrevista, a referência à leitura simultânea de textos literários, opinativos e informativos - amo ler, gosto muito mesmo. Desde pequeno, sempre li muito (...). Leio muitos livros de ficção, revistas informativas. Mas quando não tem nada pra ler até embalagem pra xampu vai (C13); Eu gosto muito de ler, éum hábito que eu tenho há um bom tempo em minha vida. Normalmente eu leio revistas, jornais, noticias e outros textos na internet, e também romances (adoro literatura nacional, como os livros de Machado de Assis), livros de crônicas, etc. (C11). Tais respostas sinalizam que, para esses sujeitos, a leitura é uma atividade que realizam desde pequenos, há um bom tempo. Percebemos no discurso desses candidatos que o prazer pela leitura estende-se por textos oriundos de vários letramentos, como o literário, o midiático e o virtual.

Em relação à escrita, esses candidatos disseram gostar de escrever textos literários e midiáticos, como o artigo de opinião, e o faziam por prazer. Dentre esses entrevistados, apenas dois destacaram o gosto pela escrita de textos tipicamente escolares, a exemplo da dissertação. Isso sinaliza um contato com mais tipos de letramento; diferentemente dos os candidatos que participaram do jogo enunciativo escolar. Talvez a familiaridade com as práticas letradas requeridas pelos eventos de letramento configurados nas agências com as quais os candidatos estabeleciam relação tenha lhes favorecido na produção textual, de modo que tais práticas fossem transpostas para o evento aqui focalizado: prova de redação.

\section{Experiência dos pais dos candidatos com a leitura e escrita}

O meio familiar do qual os candidatos faziam parte mostrou-se como outro elemento constitutivo do histórico de letramento desses sujeitos.

A vivência com práticas de leitura e de escrita dos pais dos candidatos que participaram do jogo enunciativo da prova deve ter contribuído para que 
esses desenvolvessem o hábito e o gosto pela leitura e pela escrita, pois, conforme declararam, os seus pais costumavam, em sua maioria, ler textos religiosos e principalmente textos relativos à área profissional na qual atuavam. Tal fato pode ser entendido quando levamos em consideração que esses pais eram, em geral, profissionais liberais e professores universitários, como observado nas respostas dadas ao questionário socioeconômico e cultural, áreas nas quais as atividades de leitura e escrita são intensas. Os dados indicaram também que eles gostavam de ler, em menor escala, textos ficcionais e informativos. Quanto aos textos que escreviam, eram, em sua maioria, relacionados ao trabalho e alguns à literatura; estes eram escritos por prazer, enquanto aqueles, eram decorrência da atividade profissional.

Esses dados sinalizam, assim, que as experiências letradas intrafamiliares possivelmente, aos poucos, foram incorporadas pelos filhos que tendem a atualizá-las nas agências de letramento com as quais estabelecem contato.

A experiência de leitura dos pais cujos filhos participaram do jogo enunciativo escolar mostrou-se, por sua vez, segundo os dados, limitada a textos de natureza religiosa, com exceção de um casal que não gostava de ler. Quanto à escrita, os candidatos afirmaram que seus pais não gostavam de escrever, exceto os pais do candidato 17 que, conforme ele declarou, escrevia para atender a especificidades do trabalho. Ou seja, as práticas de leitura dos pais estavam relacionadas a um único domínio diferente do domínio escolar, com o qual as famílias, de modo geral, não estabeleciam uma inter-relação direta. Por isso, essas práticas não foram mobilizadas pelos candidatos como apoio à sua participação no jogo enunciativo da prova.

Desse modo, entendemos que as práticas letradas dos pais constituemse um elemento importante para a configuração das práticas letradas dos filhos. Presenciá-los lendo e / ou escrevendo e até ser por eles estimulados para fazer o mesmo pode ser uma forma de consolidar práticas letradas. Em outros termos, o contexto no qual os sujeitos estão imersos é um dos elementos que interferem diretamente em sua escrita.

\section{Experiência dos candidatos com o gênero indicado no vestibular}

Com relação à experiência dos candidatos com o gênero produzido no vestibular, verificamos que, dentre os quatro que participaram do jogo enunciativo escolar, dois disseram ter tido contato, na escola, com o gênero produzido no vestibular, mas o nervosismo $(\mathrm{C} 14)$ e o fato de não praticar $(\mathrm{C} 15)$ havia lhes prejudicado. Sendo assim, eles tiveram contato com o gênero na 
escola, de modo que a experiência com o letramento escolar se configurou como o principal suporte / auxílio no momento da produção textual. Os outros dois candidatos apresentaram experiências diferentes. $\mathrm{O}$ terceiro candidato disse que nunca havia escrito o gênero produzido no vestibular (C16). O quarto candidato (C17) foi o único que afirmou estar acostumado a proferir palestras no seu ambiente de trabalho, mas não obteve êxito no vestibular. Isso faz supor que o fato de ter contato com o gênero não garante, necessariamente, que o sujeito saberá produzi-lo nas circunstâncias do exame vestibular, haja vista que os interlocutores, o tema e os objetivos da situação sociocomunicativa são bastante específicos. Logo, as práticas letradas requeridas no exame não coincidem, de forma biunívoca, com as exigidas pelo gênero em outros eventos.

Quanto aos candidatos que participaram do jogo enunciativo da prova, esses disseram ter tido contato com o gênero produzido no vestibular fora da escola. No caso da produção das palestras, alguns candidatos já haviam lido esse gênero em Revistas e / ou escrito por familiares - Eu vi uma ou outra escrita por meu pai e... só assistindo o resto (C8) - e outros já haviam assistido a algumas - Nunca havia lido ou escrito sobre o gênero palestra cobrado na prova de redação da UFCG, mas por já ter ouvido algumas palestras no decorrer de minha vida, mesmo não sendo sobre este tema, não vi dificuldade em escrever principalmente por se tratar de um assunto muito pessoal (C7). Nesse caso, ocorreu um ajuste da experiência pessoal dos candidatos com o que fora solicitado pela prova. Provavelmente, esse ajuste ao jogo enunciativo da prova não foi feito pelo candidato 17, anteriormente referido.

Em relação à resenha, os candidatos disseram estar acostumados a escrever esse gênero: além de já ter escrito resenhas durante a minha preparação para o vestibular, eu costumo ler resenhas criticas sobre filmes publicadas em revistas como Veja e Época (C11) e preferi a resenha por ser um gênero do qual leio gosto muito, leio muito, e também já tinha escrito algumas. Então pra mim foifácil (C13).

Notamos, assim, que esses candidatos tiveram contato com a resenha em duas agências de letramento distintas, a saber: na escolar e na midiática. Esse contato não foi, conforme disseram, limitado à leitura; eles escreveram resenhas escolares, ou seja, tinham certa familiaridade / experiência com o gênero que produziram no vestibular.

No tocante às memórias, os candidatos que participaram do JEP, embora tivessem dito que nunca haviam produzido esse gênero, eram 
habituados a escrever textos com estrutura composicional semelhante a da memória, conforme o registro a seguir:

\section{Registro 6}

C1 Sim. Gosto de escrever depoimentos como forma livre de expressar o que sinto, e isso me ajuda no meu desenvolvimento intelectual, bem como emocional; além do mais, na maioria dos casos, esses depoimentos viram letras de música, utilizados por uma banda de amigos meus; assim, sempre sou estimulada a escrever. [Grifos nossos].

\section{Registro 7}

C2 É... são contos... são... é... até narrações, eu gosto. [Grifos nossos].

\section{Registro 8}

C4 Eu faço diário. Aí também foi fácil por isso, né? Fazer o depoimento, porque eu sempre escrevo na minha agenda. [Grifos nossos].

Podemos notar em tais afirmações que, além de gostarem de escrever, os candidatos o faziam sem a imposição da tarefa escolar. Preferiam gêneros textuais em que predominam as sequências narrativa e argumentativa depoimentos, contos e diários. Entendemos que a experiência cotidiana com a escrita desses gêneros contribuiu para que tais candidatos demonstrassem as práticas letradas requeridas pela prova de redação.

As falas dos candidatos aqui focalizados sinalizam que o contato com diferentes tipos de letramento (familiar, escolar, midiático e literário) e, em alguns casos, o exercício diário de algumas das práticas desses letramentos, deve ter influenciado a produção textual no vestibular. Portanto, o contato com outros letramentos favoreceu, de modo geral, a inserção no jogo enunciativo da prova, enquanto que a familiaridade com o letramento escolar, a inserção no jogo enunciativo escolar.

\section{Considerações finais}

Considerando os objetivos traçados no presente artigo, podemos dizer que a constituição do histórico de letramento dos candidatos foi um dos elementos decisivos na participação dos jogos enunciativos tanto o da prova quanto o escolar.

Os dados demonstram que os candidatos mobilizaram na prova as práticas com as quais disseram ter mais familiaridade. Aqueles que participaram do jogo enunciativo da prova tinham um histórico de letramento com 
experiências relacionadas a práticas letradas advindas de letramentos diversos, de modo que, diante do evento de letramento proposto na prova de redação, mobilizaram práticas com as quais já tinham contato ou, pelo menos, conhecimento. Aqueles que participaram do jogo enunciativo escolar, por sua vez, mobilizaram práticas escolares, com as quais disseram ter mais familiaridade.

Tais resultados apontam para o fato de que, para obter êxito na prova de redação da UFCG, ancorada na solicitação de gêneros textuais diversos, em eventos contextualizados, os candidatos devem ter um histórico de letramento constituído não apenas de práticas escolares mas também de práticas de outros letramentos. Isso implica dizer que o letramento escolar não é suficiente nem o único que pode ajudar os candidatos a demonstrar as práticas letradas exigidas na prova de redação proposta pela UFCG.

\section{Referências}

ALMEIDA, Ana Lúcia. O professor-leitor, sua identidade e sua práxis. In: KLEIMAN, Ângela (Org.). A formação do professor. Campinas, São Paulo: Mercado de Letras, 2001. p. 115- 135.

ANDRÉ, Marli E. D. A. de. Fundamentos da pesquisa etnográfica. In: Etnografia da prática escolar. Campinas, São Paulo: Papirus, 1995. p. 15-69.

ARAÚJO, Maria do Carmo. Histórias de letramento de sujeitos egressos da educação de jovens e adultos. 106 f. 2008. Dissertação (Mestrado) - UFCG, Campina Grande, 2008.

AVELAR, Silvana Lúcia Teixeira de. Mudanças na concepção e prática de avaliação e seu efeito no ensino / aprendizagem de língua estrangeira (inglês) em uma escola de ensino médio e técnico. 2001. Dissertação (Mestrado) - Unicamp, Campinas, SP: 2001.

BARTON, David; HAMILTON, Mary. Literacy Practices. In.: BARTON, David; HAMILTON, Mary; IVANIC, Roz. Situated Literacies. London; New York: Routledge, 2000. p. 7-15.

BAZERMAN, Charles. Escrita, gênero e interação social. DIONISIO, Ângela Paiva; HOFFANAGEL, Judith Chambliss (Org.). São Paulo: Cortez, 2007.

BRASIL. Ministério da Educação. Parâmetros Curriculares Nacionais. Brasília: Ministério da Educação, Secretaria de Educação Básica, 2006.

CORREIA, Rosane Martins Duarte. O efeito retroativo da prova de inglês do vestibular da Unicamp na preparação de alunos de um curso preparatório comunitário. 2003. Dissertação (Mestrado) - Unicamp, Campinas, SP, 2003. 
COSTA VAL, Maria da Graça. Redação e textualidade. São Paulo: Martins Fontes, 1999.

GEE, James Paul. The New literacy studies. In: Situated Literacies. Reading and Writing in Contex. London: Routeledge, 2000. p. 180-197.

GUEDES-PINTO, Ana Lúcia. Narrativas de práticas de leitura: trajetórias da professora alfabetizadora. In: KLEIMAN, Ângela (Org.). A formação do professor. Campinas, São Paulo: Mercado de Letras, 2001. p. 69-94.

GUEDES-PINTO, Ana Lúcia et al. Percursos de letramento dos professores: narrativas em foco In: KLEIMAN, Angela B.; MATENCIO, Maria de Lourdes Meirelles (Org.). Letramento e formação do professor - práticas discursivas, representaçôes e construção do saber. Campinas, SP: Mercado de Letras, 2005. (Coleção Idéias sobre Linguagem, p.65-92).

HILA, Claúdia Valéria Doná. As representações do contexto de produção da redação do vestibular. In: SIMPÓSIO INTERNACIONAL DE ESTUDOS DE GÊNEROS TEXTUAIS, 4. Anais... Santa Catarina, 2007. p. 837-852.

KLEIMAN, Ângela B. (Org.). Os significados do letramento. Campinas, São Paulo: Mercado de Letras, 1995.

LANZONI, Hélcio de Pádua. Exame de proficiência em leitura de textos acadêmicos em inglês: um estudo sobre efeito retroativo. 2004. Tese (Doutorado) - Unicamp, Campinas, SP, 2004.

LEMOS, Claúdia T. G. de. Redações no vestibular: algumas estratégias. Cadernos de Pesquisa. Campinas, Unicamp - IEL, n. 23, 1977.

LIMBERTI, Rita de Cássia A. Pacheco. "Herrar" é "umano": alguns aspectos da produção textual de vestibulandos. In: LARA, Glaucia Muniz Proença. Lingua(gem), texto e discurso - entre a reflexão e a prática. Rio de Janeiro: Lucerna; Belo Horizonte: FALE/UFMG, 2006. p. 181-196.

LINODE ARAÚJO, Denise. Um "professor" no horário nobre: estudo da explicação em telejornais. 2004. Tese (Doutorado) - USP, São Paulo: 2004. p. 128-135.

MEY, Jacob L. Vozes da sociedade - Seminário de pragmática. Campinas: Mercado de Letras, 2001.

MOITA LOPES, L. P. da. Pesquisa interpretativista em Linguística Aplicada: a linguagem como condição e solução. Revista de Documentação de Estudos em Linguistica Teórica e Aplicada, Educ, v. 10, n. 2, p. 329-338, 1994.

MOREIRA, Herivelto; CALEFFE, Luiz Gonzaga. Abordagens à Pesquisa e Classificação da Pesquisa. In: Metodologia da pesquisa para o professor pesquisador. Rio de Janeiro: DP\&A, 2006. p. 39-94. 
PAVANI, Cínara Ferreira; KÖCHE, Vanilda Salton. Redação de vestibular: um gênero discursivo heterogêneo. Caderno Seminal digital, ano 12, n. 5, v. 5, jan.jun. 2006.

PÉCORA, A. Problemas de redação. São Paulo: Martins Fontes, 1986.

PILAR, Jandira. A redação como gênero. In: MEURER, José Luiz; MOTTAROTH, Désirée (Org.). Gêneros textuais e práticas discursivas. Rio de Janeiro: Lucerna, 2001. p. 159-172.

ROCCO, Maria Thereza Fraga. Crise na linguagem: a redação no vestibular. São Paulo: Mestre Jou, 1981.

SCARAMUCCI, Matilde V. Ricardi. Propostas curriculares e exames vestibulares: potencializando o efeito retroativo benéfico no ensino de LE (Inglês). Contexturas, São José do Rio Preto, v. 5, p. 97-109, 2001.

SCARAMUCCI, Matilde V. Ricardi. Vestibular e ensino de língua estrangeira (Inglês) em uma escola pública. Trabalhos em Linguística Aplicada, Unicamp, Campinas, v. 34, p. 7-29, 1999.

SCARAMUCCI, Matilde V. Ricardi; CORACINI, M. J. Apresentação. Trabalhos em Linguistica Aplicada. Unicamp, Campinas, v. 40, n. 40, p. 5-8, 2002.

SERCUNDES, Maria Madalena Iwamoto. Ensinado a escrever. In: CHIAPPINI, Lígia; GERALDI, João Wanderlei (Org.). Aprender e ensinar com textos. v. 1, São Paulo: Global, 1998. p. 21-39.

SIGNORINI, Inês. O relato autobiográfico na interação formador/formando. In.: KLEIMAN, Angela B.; MATENCIO, Maria de Lourdes Meirelles (Org.). Letramento e formação do professor - práticas discursivas, representações e construção do saber. Campinas, SP: Mercado de Letras, 2005. (Coleção Idéias sobre Linguagem, p. 93-126)

SILVA, Elizabeth Maria da Silva; LINO DE ARAÚJO. Redação e/ou gêneros textuais: caminhos de produção de textos no vestibular e no ensino médio. In: JORNADA NACIONAL DE ESTUDOS LINGUÍSTICOS DO NORDESTE, 21, Anais... João Pessoa, 2006a. p. 35-43.

SILVA, Elizabeth Maria da Silva; LINO DE ARAÚJO. Redação no vestibular e no ensino médio: um estudo sobre efeito retroativo. In: CONGRESSO DE INICIAÇÃO CIENTÍFICA, 3. Anais... Campina Grande, 2006b. p. 34-44.

SILVA, Elizabeth Maria da Silva; LINO DE ARAÚJO. Redação e/ou gêneros textuais: caminhos de produção de textos no vestibular e no ensino médio. In: JORNADA NACIONAL DE ESTUDOS LINGUÍSTICOS DO NORDESTE, 21, Anais... João Pessoa, 2006c. 
SILVA, Elizabeth Maria da Silva; LINO DE ARAÚJO. Relato de experiência no vestibular da UFCG 2005: um estudo sobre as práticas de uso da escrita. In: SEMANA DE LETRAS DA UEPB: LINGUAGENS, TECNOLOGIA E ENSINO: A PALAVRA (RE)ESCRITA E (RE)LIDA, 13, Anais... Campina Grande, 2006d.

SILVA, Elizabeth Maria da Silva; LINO DE ARAÚJO. A intertextualidade no gênero relato como uma prática de uso da escrita no vestibular da UFCG. In: ENCONTRO UNIFICADO DE ENSINO, PESQUISA E EXTENSÃO DA UFCG, 1, Anais... Campina Grande, 2005.

SILVEIRA, Rosa Maria Hessel. A entrevista na pesquisa em educação - uma arena de significados. In: COSTA, Marisa Vorraber (Org.). Caminhos Investigativos $I I$ - outros modos de pensar e fazer pesquisa em educação. Rio de Janeiro: DP\&A Editora, 2002. p.119-141.

STREET, Brian. Literacy in theory and practice. Cambridge: Cambridge University Press, 1984. p. 1-21.

VESTIBULAR UNICAMP: redações 2003. Pró-Reitoria de Graduação. Comissão Permanente para os Vestibulares. Campinas, São Paulo: Editora da Unicamp, 2003.

VÓVIO, Cláudia Lemos; SOUZA, Ana Lúcia Silva. Desafios metodológicos em pesquisas sobre letramento. In.: KLEIMAN, Angela B.; MATENCIO, Maria de Lourdes Meirelles (Org.). Letramento e formação do professor - práticas discursivas, representações e construção do saber. Campinas, São Paulo: Mercado de Letras, 2005 (Coleção Idéias sobre Linguagem, p.41-64).

ZANUTTO, Flávia; OLIVEIRA, Neil Armstrong Franco de. O gênero redação de vestibular: o que prova essa (re)produção textual? Mathesis - Revista de Educação - v. 5, n. 1, p. 83-103, jan.-jun. 2004.

Recebido em 29/04/2010. Aprovado em 09/02/2011. 